doctors into sending the "patients" in the direction they want to go or keeping them the way they are.

The ethics of such behaviour is not only a medical problem but a moral issue, with economic implications of some magnitude. Study and definition are certainly needed to clarify terms of reference.-We are, etc.,

$$
\text { L. J. F. WARnANTS. }
$$

Psychiatric Department

$$
\text { D. H. Marjot. }
$$
c/o G.P.O., Singapore.

\section{Mongolian Spots}

SIR,-For the sake of the completeness of the record an addition which should be made to Dr. D. B. Jelliffe's list (21 November, p. 1330) of races in which some neonates exhibit "Mongolian spots" is that of the Eskimos. I have frequently seen them on young Eskimo infants in Labrador, and I have no doubt they are also found in the other Eskimo communities.

As Dr. Jelliffe implies, they are of neither clinical nor ethnological significance.-I am, etc.,

Edinburgh 12.

JACK CORMack.

\section{Accidents in Coal Mines}

SIR,-On the morning on which your issue was published containing comment on Accidents in Coal Mines (5 December, p. 1411), I was attending a conference of management and union representatives called to discuss safety, and subsequently widely reported in the local press. We, working in the mining industry, would agree that it is more profitable to study working conditions; accidents, we believe, are caused, they do not just happen.

What does not emerge from your comment is the considerable problems which have arisen as a result of the technical revolution which has taken place in mining in a decade. There has been no lack of awareness among mining and safety engineers, but, as your article indicates, the problems are subtle and not always capable of easy definition.-I am, etc.,

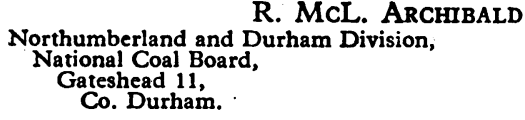

\section{Sugar and Dental Caries}

SIR,-I should like to attempt an answer to the question raised by Dr. H. Maitland Moir (5 December, p. 1463) on the relationship of breast and artificial feeding to dental caries. Whilst there is little evidence to suggest a positive relationship between breast feeding and subsequent immunity to dental decay there is an increasing awareness in the relationship of this disease to prolonged bottle feeding. ${ }^{2}$ In a recent study I have conducted into this problem (to be published) a highly positive relationship has been shown between decay in the deciduous dentition and the use of feeding bottles given to comfort children over prolonged periods of time. I was surprised to find that in a control group of pre-school children $57 \%$ had been given comforter bottles up to an average age of 1 year 11 months. Most of these bottles con- tained fresh cow's milk, but even more significant was the fact that $91 \%$ had been sweetened by the addition of sugar (sucrose).

Although these studies have only demonstrated a relationship between the prolonged use of sugared comforters and dental decay in the deciduous dentition, nevertheless a highly positive correlation has been shown between caries susceptibility in the deciduous and permanent dentition, ${ }^{3}$ thus suggesting that the prolonged use of sweetened comforter bottles in infancy and early childhood may predetermine the caries potential for many years.

In view of the significance given by Professor John Yudkin (5 December, p. 1458) to the present high consumption of sugar in this country, dental caries may be only one aspect of the problem created by the sweetened comforter bottle.-I am, etc.,

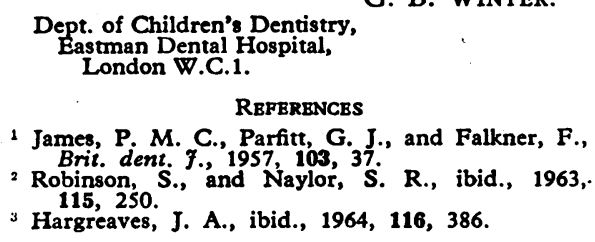
Eastman Dental Hon W.C.1. REPERENCES

1 James, P. M. C., Parfitt, G. J., and Falkner, F., Robit. dent. F., 1957 , 103, 37. .' R., ibid., 1963, $115,250$.
Hargreaves, J. A., ibid., 1964, 116, 386. G. B. WINTER.

\section{Infant Feeding}

SIR,-Dr. F. P. Hudson's letter (17 October, p. 1011) on Liga low-protein biscuits has prompted me to draw attention to two more Liga products which have a useful place in infant formulas owing to their composition and digestibility.

The "Liga three-way infant food" biscuits have been fed to healthy infants and prematures, and to infants recovering from feeding breakdowns. When added crushed in a $5-10 \%$ concentration to the appropriate milk mixture they provide a well-balanced diet up to 6 months of age. They appeal to the infants' taste and their smooth mixing quality allows concentrated bottle-feeding without blockage of the teat. To older babies the biscuit can be offered either as a snack or mixed with fruit or vegetable pulp.

The other product "Liga gluten-free" biscuits proved a well-tolerated nutrient in the treatment of coeliac disease during the crisis and later in place of gluten-free bread or other farinaceous food a valuable amplification of the reparation and maintenance diet. The difficult coeliac patient takes these biscuits well for long periods. His nutritional requirements seem adequately supplemented, as shown by the speed of recovery and the absence of relapses. - I am, etc., West Middlesex Hospital,
Isleworth, Middlesex.

$$
\text { M. DynsRi-KLein. }
$$

\section{Thyroid Nodules and Cancer}

SIR,-We read with interest but some disappointment your leading article (24 October, p. 1022). We were especially surprised to see therein no mention of the importance of directional scanning of thyroid glands in which single nodules are palpable. One of us $^{1}$ described the results of this process in a Hunterian Lecture in 1956. Of 109 " cold" nodules, $20 \%$ were definitely malignant and a further $6 \%$ possibly so; whereas of 54 " hot" and "neutral" nodules removed, none was malignant. Later ${ }^{2}$ a malignant "neutral " nodule was seen and others have reported three malignant hot nodules. ${ }^{3-5}$ This series has since become much larger but our early conclusions have not been upset by subsequent experience. If one neglects the investigation by means of radioactive iodine the overall percentage of single nodules found to be malignant was $13 \%$, twice the figure of $6.6 \%$ quoted by Veith et al. On the contrary, the incidence of cancer in multinodular glands has been found to be $8 \%$, compared with the $13.3 \%$ found by Veith et al.

Your leader lays stress on the importance of sex. The ratio of female to male patients in thyroid disorder is about $8: 1$. In thyroid carcinoma the ratio falls to $5: 1^{7}$ or even to $2: 1 .^{8}$ We therefore agree that suspicion of malignancy should be more easily aroused when the patient is a male.

We are less surely in agreement with you in the matter of age. In saying that " in women under 40 years single thyroid nodules should be removed surgically without delay" you neglect the question of whether they are " hot" or "cold" and the frequency of harmless nodularity in puberal goitres. In respiting women over the age of 40 unless the increase in size is unequivocal you seem to neglect the higher incidence of undifferentiated carcinoma in the old.

We have dealt with 150 cases of thyroid cancer in the last 10 years. Our conclusions are that cold single nodules should be removed immediately (because of the great risk of malignancy); that hot and neutral single nodules should be treated with thyroxine and removed if they do not get smaller in six months (because we have seen one malignant neutral nodule); that non-toxic multinodular goitres need only be removed if they are enlarging or causing pain or signs or symptoms of pressure despite treatment with thyroxine, undergoing a change in consistency, or in any way producing signs or symptoms suggestive of malignancy.-We are, etc.,

\section{RAYMOND GREENE.}

\section{New End Hospital, J. E. Pirrcy. \\ London N.W.3. W. SINGER.}

\section{REFBRENCBS}

I Greene, R., Ann. roy. Coll. Surg., 1957, 21, 73. Farran, H. E. A. 221 .

Med , $1956,255,65$, s Attie, J.' N., Surgery, 1960, 47, 611.

- Veith. F. Brooks, R. Grigsby, W P.

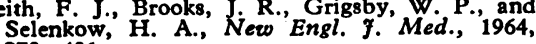

7 Piercy, J31. $\mathrm{E}$. . Postgrad. med. J., 1957, 33, 346. 1962. Blackwell, Oxford.

\section{Local Analgesics}

SIR,-In an article " To-day's Drugs" (28 November, p. 1380) it is suggested that as yet no local anaesthetic drug superior to lignocaine has appeared. I appreciate that in a review of this brevity the writer cannot cover all the advantages and disadvantages of the numerous drugs that are now available, but I am sorry to see he dismisses prilocaine so lightly.

There is no doubt that some drugs-for instance, procaine-have a special effectiveness in conduction or infiltration anaesthesia and yet little action as a topical agent. I believe that prilocaine has an action superior to lignocaine as far as the tracheobroncho tree is concerned. We have a busy endoscopy clinic in my, hospital, in which a minimum of 
750 endoscopies are performed a year. Many of these are bronchoscopies performed under premedication and local analgesia. I have described the technique very fully elsewhere. ${ }^{1}$ $M y$ work in this endoscopy clinic during the past 15 years has enabled me to form a clinical evaluation of many surface anaesthetics, and amongst those $I$ have most experience of cocaine (5\%), amethocaine (2\%), and lignocaine $(4 \%)$.

I have now had an experience extending to well over 200 endoscopies, using $4 \%$ prilocaine (Citanest), which has been supplied to me through the courtesy of Messrs. AstraHewlett, Ltd., as the drug in this strength has not yet passed the scrutiny of the Dunlop Committee. It is my opinion that this agent, when utilized in the pharynx and bronchial tree as a surface agent, has a perceptibly reduced latent period, a more effective action, and a considerably reduced toxicity, when compared with lignocaine. In these 200 cases, using an average dosage of between 6 and 8 $\mathrm{ml}$. of $4 \%$ solution ( 240 to $320 \mathrm{mg}$.) I have not seen a single case of local anaesthetic intoxication in its mildest form.

In this situation, therefore, I look upon prilocaine with particular favour, and I hope your writer's very brief notes on its performance will not dissuade other clinicians from trying out its effectiveness.-I am, etc.,

Department of Anaesthetics,
Frenchay Hospital,
Bristol.
RBFERENCE
Thoracic Anaesthesia, ed. by W. W. Mushin,
p. 410, 1963. Blackwell, Oxford.

\section{Education in First Aid}

SIR,-Your readers may recall the report of a working party set up by the Royal College of Surgeons ${ }^{1}$ which advocated, among other things, that first aid and accident prevention should be taught in schools as part of the curriculum. Subsequently, a Joint Committee publicized a report on health education in which one of their recommendations was that health education should be taught in schools. ${ }^{2}$ Not unnaturally, the first response from educationalists is that they are being asked to overload a syllabus which is already overfull. However, a most encouraging article has appeared in the Times Educational Supplement recently ${ }^{3}$ by the headmaster and the medical officer of Atlantic Collegethe recently opened international sixth-form college in Glamorgan. This article simply sets out their own approach to the teaching of first aid, health education, and accident prevention to male sixth-formers. The teaching of rescue service skills (rescue boats, cliff and beach rescue, and canoe life-guards) as a recreation is part of this school's policy of developing young men through the ideal of adventurous service to the community. The basic requirements of such training include the bronze medallion of the Royal Life Saving Society and the adult certificate in first aid of the Red Cross or St. John.

The first-aid course provides an excellent vehicle on which to hang some formal health education and accident-prevention propaganda. It is accompanied by a parallel course of scientific demonstrations in the biology laboratory.

There are a number of considerations of importance to the medical profession that arise. To what extent is first aid or health education being taught in our schools? What should be its content ? To what extent does the medical profession present a united front with a uniform standard of teaching in first aid and health education ? In what way can teachers of first aid obtain help from the profession in the content of their lectures and the ancillary aids necessary for good presentation? Are we satisfied that the present first-aid methods reflect what we in medicine feel should be taught to the lay public ? Do doctors, called upon to train people for firstaid certificates, set a sufficiently high and uniform standard of teaching and marking ? Would it be of value to press for formal firstaid teaching in all the schools, and at what age should it start ? What about the doctors ; should they not, as undergraduates, receive the same basic and advanced training in first aid ?

Could not television do more to provide reliable instruction? I would welcome some answers to these questions either privately or through your columns.-I am, etc.,

\section{Medical Commission on Acciden \\ Prevention \\ oyal College of Surgeons, \\ London W.C.2.}

Norman Capener.

\section{REFERENCES}

1 Report of Working Party on Accident Prevention and Life Saving. Royal

Report of a Joint Committee of the Central and Scottish Health Services Councils on Health Education, Chapter 10, 1964. H.M.S.O. London.

Hoare, D. J., and Llewellyn, D. J., Times Educa tional Supplement, 18 September 1964, p. 394.

\section{Mongolism : When Should Parents be Told?}

SIR,-I regret that I am not entirely convinced by the article of Dr. C. M. Drillien and Sister E. M. Wilkinson (21 November, p. 1306) that a mother should be told immediately after birth that her child is found to be a mongol. I note also that their conclusions have the approval of Professor R. S. Illingworth (5 December, p. 1459) and I venture, with respect, to make the following remarks.

What I am really not convinced about is whether a mother, who already knows that her child is a mongol, is likely to be entirely honest with the doctors, and with herself when she says that she would like to be told as soon as possible. I feel that if mothers of normal children were to be asked this question-" Suppose your child were mongol, when would you like to be told ?" -then their replies might not be so definite.

One of the great joys of motherhood is the peace and contentment which comes with the arrival of a new baby. The delivery of the baby is surely the completion of a valuable and natural act, and in my view the mother's enjoyment of the discovery of things about her baby is sacred, and should not be disturbed unless absolutely necessary. In the event of a child being born with an abnormality which is immediately obvious, such as a hare-lip, then there is nothing that any doctor can do to protect her from the sudden crashing awareness of the defect. The sadness and depression which comes over a family on these occasions is a state with which most general practitioners must be familiar, and it can be most heart-rending to behold.
In the case of the mongolism, however, the doubts about the normality of her baby dawn upon the mother slowly-indeed, she may almost shut her eyes to the defects for a time, seeing in her child only the good points, and disregarding all others-and, provided she has available at all times the counsel of her family doctor, I do not think she can come to much harm. After all, why should she be told immediately? If it is just to save her worrying, then it seems to me to be of doubtful value to replace worry by sadness and defeat. In the relatively few mongols that I have had to deal with as a general practitioner over the last 15 years I have usually made a point of seeing the babies more frequently than usual, for checks of weight and so on, and it is possible to spot the moment when the mother's doubts begin to arise. On this occasion leading questions may be asked, and thus facilitate the opening of the discussion about the child's possible defects. I believe that in this way the information about mongolism in her baby is passed to the mother much more gently than would be the case if she were told earlier on. Since she has already learnt for herself that the child is not abnormal in every respect, and is not completely unresponsive to her, then she readily understands that her efforts in producing this baby have not been entirely without recompense.

The diagnosis of mongolism is not always easy, and I think it may be downright unkind to tell a mother immediately after birth, particularly if there is a risk that the doctor may be wrong. Professor Illingworth indicates a similar point in his letter. What I am suggesting is not an avoidance of the doctor's responsibility, for he must be prepared to speak with authority, and to take some definite action, immediately the occasion arises. I think, however, that there should be a deliberate delay in order to allow the mother time to get to know her baby. In my experience, between two and three months seems to be appropriate.-I am, etc.,

$$
\begin{gathered}
\text { Barnard Castle, } \\
\text { Co. Durham. }
\end{gathered}
$$

K. H. PICKWORTH.

\section{Specialty of Chest Medicine}

SIR,-Dr. Neville C. Oswald's account of the specialty of chest medicine (10 October, p. 935) has interested all who work in this field and who are concerned with the way this specialty will develop in the future.

When "integration" is discussed there is a widespread tendency to overlook the sheer volume of work handled by chest physicians throughout the country. Some statistics for 1961 in regard to the area served by the Wessex Regional Hospital Board serve to illustrate this. For a population of $1,665,000$ there were 13,328 new out-patients referred to the chest clinics, compared with 17,225 new out-patients referred to the general medical departments in the Region. The outpatient attendances of " old cases" amounted to 54,635 at the chest clinics, and 76,533 at the general medical departments. In other words it would appear that general physicians see 4.5 "old cases" per new referral, whereas chest physicians see 4.1. These data are especially interesting, since Dr. Oswald's analysis of 25 representative chest clinics indicates that half the out-patient attendances of "old cases" at chest clinics nowadays are non-tuberculous patients. 